\title{
A study of the relationship between neurological function and serum vitamin $E$ concentrations in patients with cystic fibrosis
}

\author{
HJ WILLISON, ${ }^{*}$ DPR MULLER, $\uparrow$ S MATTHEWS, $\uparrow$ JONES, $\ddagger$ A KRISS, RJ STEAD,* \\ ME HODSON, * AE HARDING $\ddagger$
}

From Brompton Hospital and the Cardiothoracic Institute, ${ }^{*}$ the Institute of Child Health, $\dagger$ and the Institute of Neurology, $\ddagger$ London, $U K$

SUMMARY A patient with cystic fibrosis and undetectable serum vitamin $\mathrm{E}$ concentrations is described who developed a progressive spinocerebellar syndrome and pigmentary retinopathy with abnormal somatosensory and visual evoked potentials (SSEPs and VEPs). In order to assess the relationship between neurological function and serum vitamin $E$ concentrations in cystic fibrosis, 29 unselected patients who had no neurological symptoms were examined neurologically. Ten were randomly selected for neurophysiological assessment by recording SSEPs and VEPs. Electroretinograms (ERGs) were also performed in five cases. The findings were correlated with serum vitamin $\mathrm{E}$ concentrations which were unknown to the neurological investigators prior to completion of the study. Only one patient had definite reflex and sensory abnormalities, and the remaining 28 were clinically normal. The ERG was abnormal in two cases, one of whom had abnormal VEPs. SSEPs were normal in all 10 cases. Twenty six patients had serum vitamin $E$ concentrations below the normal range. In two of the three patients who had definite neurological or electrophysiological abnormalities serum vitamin $\mathrm{E}$ concentrations were below the median value for the whole group.

Severe vitamin E deficiency as a consequence of prolonged fat malabsorption is now a well established cause of a progressive neurological disorder comprising ataxia, areflexia, and proprioceptive loss. This syndrome is particularly prevalent in children with abetalipoproteinaemia and chronic liver disease. ${ }^{1}$ It has also been reported after extensive ileal resection ${ }^{23}$ and in a few cases of cystic fibrosis. ${ }^{4-6}$ Pathological studies in $\operatorname{man}^{78}$ and experimental animals ${ }^{9}$ have shown that vitamin $\mathrm{E}$ deficiency produces a dying-back neuropathy in sensory neurons which affects the centrally directed fibres in the posterior columns more severely than the peripheral axons. Mild degenerative changes also occur in the spinocerebellar tracts. ${ }^{7}$

Reduced serum concentrations of vitamin $\mathrm{E}$ are common in patients with cystic fibrosis, but it is not

Address for reprint requests: Dr DPR Muller, Department of Child Health, Institute of Child Health, 30 Guilford Street, London WC1N 1EM.

Received 11 January 1985 and in revised form 26 March 1985. Accepted 5 April 1985 clear how often these are of clinical or pathological significance. This paper describes a patient with undetectable serum vitamin $E$ concentrations who developed a spinocerebellar syndrome and a pigmentary retinopathy. The results of a study correlating vitamin $E$ status with clinical and neurophysiological observations in 29 neurologically asymptomatic cases of cystic fibrosis are also reported.

\section{Case report}

A 22-year-old woman with cystic fibrosis presented with meconium ileus in infancy. She had steatorrhoea and recurrent chest infections throughout childhood, and a number of episodes of jaundice before the age of five. Hepatomegaly was first noted when she was 12 , and on investigation it appeared that her liver disease resulted from chronic active hepatitis. At the age of $14 \mathrm{yr}$ she complained of night blindness and was found to have a pigmentary retinopathy. This was attributed to a documented severe deficiency of vitamin A but her symptoms progressed despite replacement therapy. Serum vitamin A concentrations increased but remained below the normal 


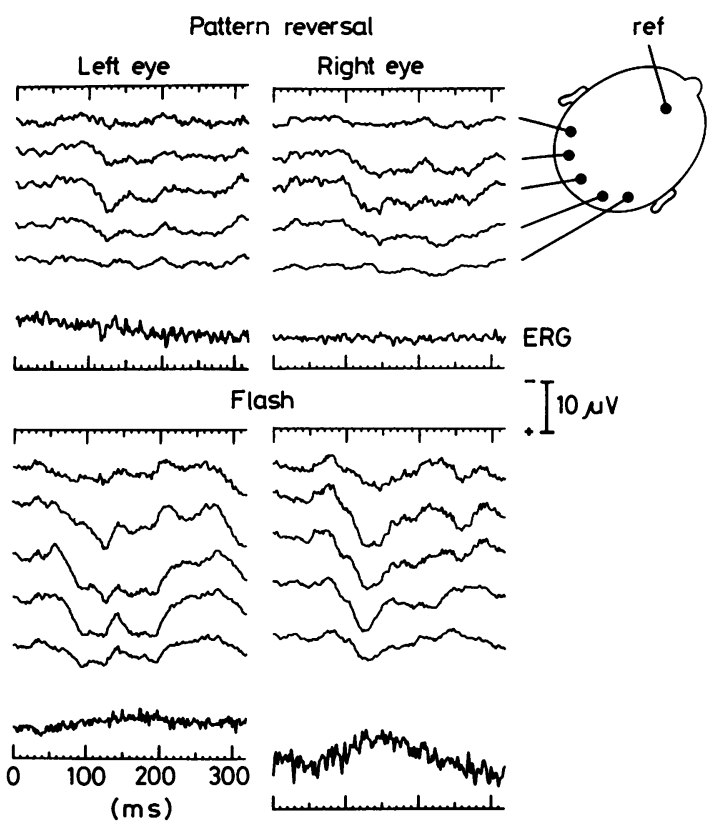

Fig 1 Visual evoked potentials and electroretinograms to pattern reversal and flash in 22-year-old patient with cystic fibrosis. The occipital responses to pattern reversal are delayed and electroretinograms to both pattern and flash stimulation are severely degraded.

range $(>20)$ at around $12 \mu \mathrm{g} / 100 \mathrm{ml}$. Four years later she became aware of progressive unsteadiness of gait, and at the age of 20 she developed clumsiness of the hands and slurring of speech. On examination she was thin with clubbed fingers and signs of chronic chest disease and hepatosplenomegaly. Visual acuity was $6 / 18$ bilaterally, with absent colour vision, constricted visual fields and impaired dark adaptation. Fundoscopy showed extensive atrophy of the

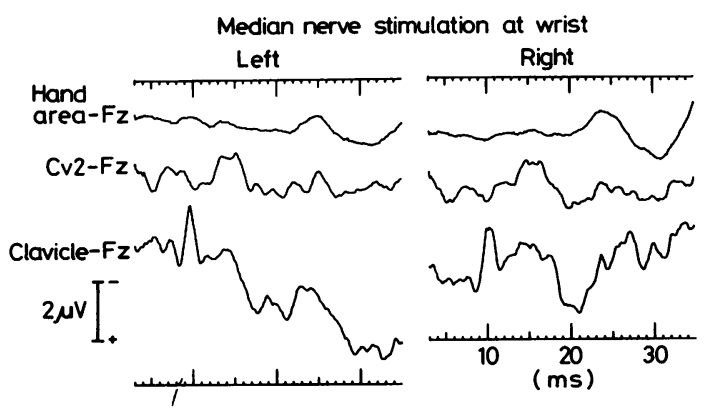

Fig 2 Clavicular and cervical components of somatosensory evoked potentials from the patient referred to in fig 1 are oflow amplitude but normal latency. There is marked delay of the initial negative potential recorded over the cortical hand area. retinal pigment epithelium with fine pigment migration. There was bilateral ptosis, anisocoria, abnormal horizontal and vertical eye movements, and first degree nystagmus on lateral gaze. She had a cerebellar dysarthria and clumsy tongue movements. There was weakness of ankle and toe dorsiflexion, and ataxia of all four limbs with areflexia and flexor plantar responses. Proprioception, vibration sense, light touch appreciation and two point discrimination were impaired distally, more in the legs than the arms. She had a broad based ataxic gait with bilateral foot drop.

A full blood count was normal and no acanthocytes were present. Serum vitamin B12 and folate were normal. Total bilirubin was $29 \mu \mathrm{mol} / \mathrm{l}$ (normal <17); the hepatic enzymes were elevated (alkaline phosphatase $2247 \mathrm{iu} / \mathrm{l}$, SGOT $163 \mathrm{iu} / \mathrm{l}$ and gamma GT $309 \mathrm{iu} / \mathrm{l}$; normal <300, 35 and 33 respectively). A fasting blood glucose was marginally high at $7.5 \mathrm{mmol} / 1$ (normal $<6.0)$. Serum cholesterol was normal at $3 \cdot 2 \mu \mathrm{mol} / \mathrm{l}$. Serum vitamin $\mathrm{E}$ was undetectable, but serum vitamin $A$ was now in the normal range at $29 \mu \mathrm{g} / 100 \mathrm{ml}$. Cerebrospinal fluid examination and a CT brain scan were normal. Nerve conduction studies showed evidence of an axonal sensory neuropathy. VEPs were bilaterally delayed and degraded with P100 latencies of 127 (left eye) and $133 \mathrm{~ms}$ (right eye) (fig 1). The ERG was not detectable from either eye following pattern reversal and was very degraded following flash stimulation. SSEPs recorded over the clavicle (N9) and cervical spine (N13) following median nerve stimulation at the wrist were of marginally low amplitude but normal latency; over the sensory cortex the initial response (N20) was markedly delayed at $25.3 \mathrm{~ms}$ (fig 2). Brain stem auditory evoked potentials (BSAEPs) were normal.

Treatment with oral and intramuscular vitamin $\mathrm{E}$ preparations was commenced in August 1983, but serum vitamin $\mathrm{E}$ concentrations were within the normal range for only two months before she was admitted to hospital with intestinal obstruction. She required hospitalisation for four months because of recurrent intra-abdominal sepsis, deterioration in liver function, and gastrointestinal bleeding. During her admission vitamin E supplements were withdrawn and her vision deteriorated. She remained weak and generally unwell until July 1984 but has subsequently improved slowly. Oral and intramuscular vitamin E supplements were reintroduced in May 1984.

On examination in February 1985 she had marked jaundice. Visual acuity was $6 / 24$ on the right and $3 / 60$ on the left, with severe constriction of the visual fields. Apart from more extensive loss of pain and touch appreciation below the knees the neurological examination had not changed significantly since July 1983 . Her gait was ataxic and uncertain but this was clearly partly related to her visual loss. Serum vitamin E concentration was $23.8 \mu \mathrm{mol} / \mathrm{l}$ (normal 11·5-35).

\section{Patients and methods}

Patients with cystic fibrosis admitted to the Brompton Hospital, London, were investigated. They were included in the study if they were not known to have any neurological symptoms, had not received vitamin E supplements, had normal serum concentrations of vitamin B12 and folate, and had either normal or only mildly impaired glu- 
Table Serum vitamin $E$ and vitamin $A$ concentrations and vitamin E/cholesterol ratios in patients with cystic fibrosis

\begin{tabular}{|c|c|c|c|}
\hline Case no & Vitamin $E(\mu \mathrm{mol} / \mathrm{l})$ & Vitamin E/cholesterol ( $\mu \mathrm{mol} / \mathrm{mmol})$ & Vitamin $A(\mu \mathrm{g} / 100 \mathrm{ml})$ \\
\hline $\begin{array}{l}1 \dagger \\
2^{*} \\
3 \\
4 \\
5 \\
6 \\
7 \\
8^{*} \\
9 \\
10 \\
11 \\
12 \\
13 \\
14 \\
15 \\
16 \\
17 \\
18 \\
19 \\
20 \\
21 \\
22 \\
23 \\
24 \\
25 \\
26 \\
27 \\
28 \\
29\end{array}$ & $\begin{array}{c}0.18 \\
3 \cdot 4 \\
3 \cdot 4 \\
0 \\
3 \cdot 5 \\
4 \cdot 0 \\
5 \cdot 1 \\
6 \cdot 0 \\
3 \cdot 9 \\
5 \cdot 0 \\
9 \cdot 5 \\
8 \cdot 1 \\
4 \cdot 7 \\
0 \\
8 \cdot 2 \\
11 \cdot 3 \\
17 \cdot 7 \\
15 \cdot 4 \\
3 \cdot 8 \\
1.9 \\
0 \\
0 \cdot 8 \\
6 \cdot 6 \\
12 \cdot 3 \\
4 \cdot 4 \\
0 \\
2 \cdot 8 \\
3.7 \\
3 \cdot 5\end{array}$ & $\begin{array}{l}0.05 \\
1.06 \\
1.17 \\
0 \\
1.18 \\
1.05 \\
1.96 \\
1.42 \\
0.96 \\
2.25 \\
3.01 \\
1.49 \\
0 \\
1.87 \\
4.93 \\
5.65 \\
3.93 \\
0.96 \\
0.73 \\
0 \\
0.19 \\
1.61 \\
2.38 \\
1.53 \\
0 \\
1.23 \\
1.85 \\
-\end{array}$ & $\begin{array}{l}14 \\
28 \\
29 \\
29 \\
21 \\
23 \\
33 \\
20 \\
23 \\
17 \\
= \\
= \\
= \\
= \\
= \\
= \\
= \\
= \\
= \\
= \\
= \\
=\end{array}$ \\
\hline $\begin{array}{l}\text { normal range } \\
\text { (mean } \pm 2 \text { SD) }\end{array}$ & $11 \cdot 5-35 \cdot 0$ & $2 \cdot 1-8 \cdot 6$ & $>20$ \\
\hline
\end{tabular}

cose tolerance. Those requiring hypoglycaemic drugs were excluded. Twenty nine patients were studied; their mean age was 24 (range 14-37) years. They were examined neurologically by either one or two of the authors (HJW and $\mathrm{AEH}$ ), and their serum vitamin $\mathrm{E}$ concentrations were estimated colorimetrically. ${ }^{10}$ The vitamin $E$ concentrations were unknown to the neurological investigators prior to completion of the study. Ten patients (Nos 1-10, table) were randomly selected for neurophysiological evaluation by means of visual, somatosensory, and brain stem auditory evoked potentials (BSAEPs), performed as previously described." ${ }^{11}$ Serum vitamin A concentrations were also measured in these 10 patients by high performance liquid chromatography. ${ }^{12}$ Electroretinograms from each eye were recorded in five cases using a skin electrode on the lower eyelid referred to another on the outer canthus.

\section{Results}

Of the 29 patients investigated, serum vitamin E concentrations were reduced in 22 and undetectable in four, with a median value of $3.9 \mu \mathrm{mol} / \mathrm{l}$ (reference range 11.5 $35 \mu \mathrm{mol} / \mathrm{l})$ (table). Vitamin E status was also assessed by expressing the serum vitamin $E$ concentration relative to the total cholesterol concentration. ${ }^{13}$ If this ratio is used as an index of vitamin $E$ deficiency, three patients who had serum vitamin $\mathrm{E}$ concentrations below the lower limit of normal had normal ratios. The opposite did not occur. Two patients had reduced serum vitamin A concentrations (table).

On neurological examination, only one patient was clearly abnormal, with depressed or absent tendon reflexes, mildly reduced proprioception at the toes and Rombergism. Peripheral sensory and motor nerve conduction studies were normal. His serum vitamin $E$ concentration and vitamin $\mathrm{E} /$ cholesterol ratio were very low at $0.18 \mu \mathrm{mol} / \mathrm{l}$ and 0.05 respectively; he also had a markedly reduced serum vitamin A concentration.

In all 10 patients studied SSEPs to upper and lower limb stimulation and BSAEPs were normal compared to age and sex matched controls studied in the same laboratory. There was no correlation between latency or amplitude of any of the SSEP components and serum vitamin $E$ concentrations. Two of the five patients tested had bilaterally abnormal flash ERGs, with marked attenuation of the second (positive going ' $b$ ' wave) component. One of these had prolonged VEP latencies of 119-123 ms, 4-8 ms over the upper limit of normal. Both abnormal cases had reduced serum vitamin $E$ concentrations and vitamin $E /$ cholesterol ratios, but normal vitamin A concentrations (table). There was no correlation between VEP amplitude or latency and serum vitamin $A$ or vitamin $E$ concentrations in the 10 patients investigated.

\section{Discussion}

The neurological disorder observed in the patient described in the case report, which consisted of ataxia, areflexia, loss of joint position and vibration sense, ptosis and ophthalmoplegia, is similar to that previously described in vitamin $\mathrm{E}$ deficiency associ- 
ated with chronic fat malabsorption. ${ }^{124714}$ Pigmentary retinopathy is common in untreated abetalipoproteinaemia and has been reported in a small number of patients with other fat malabsorptive syndromes. ${ }^{3}$ is

Overt neurological disease associated with vitamin $\mathrm{E}$ deficiency is relatively rare in cystic fibrosis. Its occurrence has only previously been reported in detail in three cases. ${ }^{45}$ The patient with cystic fibrosis described here had severe liver disease which gives rise to reduced luminal bile salt concentrations and therefore impaired solubilisation and absorption of vitamin E. ${ }^{16}$ It is of interest that one of the other reported cases of cystic fibrosis with a spinocerebellar syndrome had had multiple ileal resections ${ }^{5}$ which would result in reduced reabsorption and increased excretion of bile salts and a reduction in size of the bile salt pool. The luminal concentration of bile salts in another patient $t^{4}$ was below the critical micellar concentration.

Detailed clinical assessment of 29 unselected patients with cystic fibrosis showed definite neurological abnormalities in only one. Most patients had symptomatic steatorrhoea (range 0.9$39 \mathrm{~g}$ faecal fat/day) which was controlled to a varying extent by pancreatic enzyme supplements. None had severe liver disease. Nevertheless, all but three patients had low serum concentrations of vitamin $E$ and in four the vitamin was undetectable. When vitamin $E$ status was expressed as the serum vitamin $\mathrm{E} /$ cholesterol ratio, six patients fell into the normal range. This difference reflects the mild hypocholesterolaemia observed in the patient group which results from fat malabsorption. The neurologically abnormal patient had greatly reduced serum vitamin E concentrations but no definite correlation could be obtained between clinical neurological dysfunction and vitamin $E$ status in the series as a whole.

The prominent central sensory axonopathy which underlies the spinocerebellar syndrome associated with vitamin $E$ deficiency can be demonstrated by the use of SSEPs in symptomatic patients, showing delay in conduction between the cervical spinal cord and the sensory cortex ${ }^{23}{ }^{17}$ SSEPs were normal in all the asymptomatic cases studied here, including the one with mild but definite clinical abnormalities suggesting posterior column dysfunction. This observation implies that the SSEP is not sensitive enough to reflect minor, but clinically significant, degenerative changes in the posterior columns in this syndrome.

The finding of ERG abnormalities in two cases indicates the presence of subclinical retinal dysfunction, the aetiology of which is not clear. Serum vitamin E concentrations were not excessively low compared to the group as a whole, and vitamin A concentrations were normal. Experimental data suggest that either vitamin $\mathrm{E}$ or $\mathrm{A}$ deficiency can result in retinal degeneration, and that combined deficiency has a synergistic harmful effect on photoreceptor cells, probably because vitamin E deficiency accentuates light induced peroxidative retinal damage and increases oxidative destruction of stored vitamin A. ${ }^{18-20}$

A possible relationship between retinal dysfunction and a deficiency of vitamin $E$ and/or vitamin $A$ is also evident from clinical studies in patients with severe fat malabsorption. Clinical and electroretinographic improvement has been described after the administration of vitamin $A$ alone to patients with retinopathy associated with abetalipoproteinaemia. ${ }^{21} 22$ However, a child with abetalipoproteinaemia developed a retinopathy despite having normal serum concentrations of vitamin A. ${ }^{23}$ Since commencing vitamin E supplementation 17 years ago her retinopathy has not progressed. ${ }^{24}$ Several of the patients with vitamin E deficiency secondary to chronic cholestasis reported by Alvarez and colleagues ${ }^{15}$ had clinical and electrophysiological evidence of retinal dysfunction in the presence of normal serum vitamin A concentrations.

It is possible that the VEP abnormalities observed in one of the patients in this study, and also that described in the case report, were secondary to retinal dysfunction, but delayed VEP latencies have recently been reported in a patient with cystic fibrosis and a spinocerebellar syndrome in whom the ERG was normal. ${ }^{25}$ These reverted to normal after two months of vitamin $\mathrm{E}$ therapy. As far as we are aware, the optic nerves have not been examined pathologically in either human or experimental vitamin E deficiency. Optic neuropathy has been attributed to prolonged chloramphenicol therapy in patients with cystic fibrosis, and it is possible that this predisposition is related to vitamin deficiencies. ${ }^{26}$ None of the patients in the present study had received prolonged chloramphenicol therapy.

Neurological abnormalities have been found in $1.5 \%$ and $2.5 \%$ of patients in two previous series of cases of cystic fibrosis. ${ }^{27}$ Although the studies are not directly comparable because of different selection and assessment criteria, one of the present series of 29 was found to have definite clinical abnormalities and two were abnormal on neurophysiological grounds.

The relationship between serum vitamin $E$ concentrations and these findings is not a simple one, as has been observed previously. ${ }^{28}$ It is reasonable to suggest that the development of a spinocerebellar syndrome and severe vitamin $\mathrm{E}$ deficiency are causally related as a number of deficient patients with ataxic syndromes have improved objectively after 
vitamin E supplementation. ${ }^{14}$ Vitamin E deficiency needs to be prolonged before neurological dysfunction develops. Patients with abetalipoproteinaemia have undetectable serum concentrations of vitamin $E$ from birth, but do not usually have neurological symptoms until the second decade of life..$^{29}$ Neuropathological studies have demonstrated that there is a high incidence of axonal degeneration in the rostral parts of the posterior columns in the spinal cord of patients with cystic fibrosis, a lesion characteristic of vitamin E deficiency. ${ }^{3031}$ The incidence of this finding increases with age in untreated patients but appears to have fallen since the introduction of vitamin $E$ supplementation in cystic fibrosis in the United States. ${ }^{30}$

In view of the uncertainty about the degree of vitamin $\mathrm{E}$ deficiency required to cause neurological dysfunction in cystic fibrosis, it seems prudent to suggest that serum vitamin $E$ concentrations are measured regularly in all patients, and that these are maintained within the normal range by means of appropriate supplementation. We have treated patients with uncomplicated cystic fibrosis with a fat soluble oral preparation of alpha tocopheryl acetate (Ephynal-Roche) and found that normal serum vitamin $\mathrm{E}$ concentrations could generally be achieved after one month on a dose of $10 \mathrm{mg} / \mathrm{kg} /$ day. Thereafter a lower dose of $200 \mathrm{mg} /$ day appeared sufficient to maintain concentrations within the normal range (Muller et al, unpublished observations).

A policy of supplementing deficient patients would be more practical than performing regular detailed neurological assessments and starting treatment only when neurological dysfunction becomes clinically evident. It would have the important advantage of preventing neurological disability which is likely to become more prevalent as the population of patients with cystic fibrosis grows older owing to improved medical management.

We thank Drs JC Batten and R Knight for allowing us to study patients under their care, and Dr C Kemp (Institute of Visual Science, London) for performing the vitamin A assays. Dr Muller thanks Hoffmann-La Roche for their support and Dr Stead was supported by the Augustus and Frances Newman Foundation.

\section{References}

' Muller DPR, Lloyd JK, Wolff OH. Vitamin E and neurological function. Lancet 1983;i: 225-8.

${ }^{2}$ Harding AE, Muller DPR, Thomas PK, Willison HJ. Spinocerebellar degeneration secondary to chronic intestinal malabsorption: a vitamin $\mathrm{E}$ deficiency syndrome. Ann Neurol 1982;12:419-24.

${ }^{3}$ Howard L, Oveson L, Satya-Murti S, Chu R. Reversible neurological symptoms caused by vitamin $\mathrm{E}$ deficiency in a patient with short bowel syndrome. Am J Clin Nutr 1982;36: 1243-9.

${ }^{4}$ Elias E, Muller DPR, Scott J. Spinocerebellar disorders in association with cystic fibrosis or chronic childhood cholestatis and virtually undetectable serum concentrations of vitamin E. Lancet 1981;ii:1319-21.

s Bye AME, Muller DPR, Wilson J, Wright VM, Mearns MB. Symptomatic vitamin E deficiency in a patient of 10 years with cystic fibrosis. Arch Dis Child 1985;60: $162-4$.

${ }^{6}$ Umetsu DT, Couture P, Winter HS, Kagan BM, Bresnan MJ, Lux SE. Degenerative neurological disease in patients with acquired vitamin E deficiency. Pediatr Res 1980;14:512.

${ }^{7}$ Rosenblum JL, Keating JP, Prensky AL, Nelson JS. A progressive neurologic syndrome in children with chronic liver disease. $N$ Engl J Med 1981;304:503-8.

${ }^{8}$ Geller A, Gilles F, Shwachman H. Degeneration of fasciculus gracilis in cystic fibrosis. Neurology (Minneap) 1977; 27:185-7.

${ }^{9}$ Nelson JS, Fitch CD, Fischer VW, Broun GO, Chou AC. Progressive neuropathologic lesions in vitamin E deficient rhesus monkeys. J Neuropathol Exp Neurol 1981;40:166-86.

${ }^{10}$ Muller DPR, Harries JT, Lloyd JK. The relative importance of the factors involved in the absorption of vitamin $\mathrm{E}$ in children. Gut 1974;15:966-71.

"Walser H, Kriss A, Cunningham K, Halliday AM, Jones SJ, Taube D. A multimodal evoked potential assessment of uraemia. In: Nodar RH, Barber C, eds. Evoked Potentials II, Boston: Butterworth, 1984:643-9.

${ }^{12}$ Bieri JG, Tolliver TBS, Catignani GL. Simultaneous detection of alpha tocopherol and retinol in plasma or red cells by high performance liquid chromotography. Am J Clin Nutr 1979;32:2143-9.

${ }^{13}$ Farrell PM, Levine SL, Murphy MD, Adam AJ. Plasma tocopherol levels and tocopherol-lipid relationships in a normal population of children as compared to healthy adults. Am J Clin Nutr 1978;31:1720-6.

${ }^{14}$ Guggenheim MA, Ringel SP, Silverman A, Grabert BE. Progressive neuromuscular disease in children with chronic cholestasis and vitamin E deficiency: diagnosis and treatment with alpha tocopherol. J Pediatr 1982; 100:51-58.

is Alvarez F, Landrieu P, Laget P, Lemonnier F, Odievre $M$, Alagille D. Nervous and ocular disorders in children with cholestasis and vitamin $A$ and $E$ deficiencies. Hepatology 1983;3:410-4.

${ }^{16}$ Harries JT, Muller DPR. Absorption of vitamin E in children with biliary obstruction. Gut $1971 ; 12: 579$ 84.

${ }^{17}$ Harding AE, Jones S, Booth IW, Ellis CJK, Muller DPR. Spinocerebellar degeneration related to a selective defect of vitamin E absorption. $N$ Engl Med J 1985 (in press).

${ }^{18}$ Hayes KC. Retinal degeneration in monkeys induced by deficiencies of vitamin E or A. Invest Ophthalmol Vis 
Sci 1974; 13:499-510.

${ }^{19}$ Robison WG, Kuwabara T, Bieri JG. Deficiencies of vitamins $E$ and $A$ in the rat: retinal damage and lipofuscin accumulation. Invest Ophthalmol Vis Sci 1980;19:1030-7.

${ }^{20}$ Anonymous. The effect of deficiency of vitamins $\mathrm{E}$ and A on the retina. Nutr Rev 1980;38:386-9.

${ }^{21}$ Gouras P, Carr RE, Gunkel RD. Retinitis pigmentosa in abetalipoproteinemia. Effects of vitamin A. Invest Ophthalmol Vis Sci 1971;10:784-93.

${ }^{22}$ Sperling MA, Miles DA, Kennerdell JS. Electroretinographic responses following vitamin $A$ therapy in abetalipoproteinaemia. Am J Ophthalmol 1972; 73:342-51.

${ }^{23}$ Wolff OH, Lloyd JK, Tonks EL. Abetalipoproteinaemia with special reference to the visual defect. Exp Eye Res 1964;3:439-42.

${ }^{24}$ Muller DPR, Lloyd JK. Effect of large oral doses of vitamin $E$ on the neurological sequelae of patients with abetalipoproteinaemia. Ann NY Acad Sci 1982;393: 133-44.

${ }^{25}$ Messenheimer JA, Greenwood RS, Tennison MJ, Brickley JJ, Ball CJ. Reversible visual evoked potential abnormalities in vitamin $\mathrm{E}$ deficiency. EEG Journal
1984; 56:32P.

26 Tomasi LG. Neurological complications in cystic fibrosis. In: Lloyd-Still JD, ed. Textbook of Cystic Fibrosis. Bristol: John Wright, 1983:383-408.

${ }^{27}$ Shwachman H, Kowalski M, Khaw K-T. Cystic fibrosis: a new outlook: 70 patients above 25 years of age. Medicine (Baltimore) 1978;56:129-49.

${ }^{28}$ Chabria S, Tomasi LG, Lloyd-Still JD. Neurological manifestations of cystic fibrosis: lack of relationship to vitamin E deficiency. Ann Neurol 1978;4:194 (abstr).

${ }^{24}$ Herbert PN, Assmann G, Grotto AM, Fredrickson DS. Familial lipoprotein deficiency. In: Stanbury JH, Wyngaarden JB, Fredrickson DS, Goldstein JL, Brown MS, eds. The Metabolic Basis of Inherited Disease, 5th edition. New York: McGraw-Hill, 1983:589-621.

${ }^{30}$ Sung JH, Park SH, Mastri AR, Warwick WJ. Axonal dystrophy in the gracile nucleus in congenital biliary atresia and cystic fibrosis (mucoviscidosis): beneficial effect of vitamin E therapy.J Neuropathol Exp Neurol 1980;39:584-97.

${ }^{31}$ Cavalier SJ, Gambetti P. Dystrophic axons and spinal cord demyelination in cystic fibrosis. Neurology $(N Y)$ 1981;31:714-8. 